\title{
Primary health care in Africa: Now more than eVer!
}

Author:

Jan De Maeseneer ${ }^{1}$

\section{Affiliation:}

${ }^{1}$ Department of Family Medicine and Primary

Health Care, Ghent

University, Belgium

\section{Correspondence to:}

Jan De Maeseneer

e-mail:

jan.demaeseneer@ugent.be

\section{Postal address:}

University Hospital - 1K3,

Department of Family

Medicine and Primary

Health Care, 185 De Pinte

Lane, B-9000 Ghent,

Belgium

\section{Keywords:}

community-oriented primary care (COPC) strategy; primary health care teams; family medicine; Millennium

Development Goals; Africa

\section{Dates:}

Received: 17 Aug. 2009

Accepted: 20 Aug. 2009

Published: 30 Sept. 2009

How to cite this article: De Maesseneer J. Primary health care in Africa:

Now more than ever! Afr J Prm Health Care Fam Med. 2009;1(1), Art. \#112, 3 pages. DOI: $10.4102 /$ phcfm. v1i1.112

\section{Note:}

This article is a summary of the 13th lecture in memory of Dr Andem Ewa, founder and first president (1976-1986) of the Association of General and Private Medical Practitioners of Nigeria. Dr Andem Ewa was also the first chairperson of the Faculty Board of the Faculty of General Medical Practice of the National Postgraduate Medical College of Nigeria.

(C) 2009. The Authors. Licensee: OpenJournals Publishing. This work is licensed under the Creative Commons Attribution License.

\section{Accessing primary health care in the 21st century}

Nowadays, society worldwide is characterised by important changes and developments, including those relating to the demographic and epidemiological, to the scientific and technological, to the socio-economic and the cultural, and to globalisation and 'glocalisation'.

The Millennium Development Goals set targets to be achieved by all the different regions of the world by 2015. Unfortunately, all regions are currently off track in terms of at least some of the goals, with the two regions that are lagging the most (namely, Southern Asia and sub-Saharan Africa) being off track on all of the goals. The situation regarding children's nutrition is problematic in many parts of Africa. Many African countries are not making sufficient progress in reducing the rates of child and maternal mortality. The number of HIV/AIDS cases is also continuing to increase worldwide. In many countries, much more effort must be exerted to reach the poor. ${ }^{1}$ A new global commitment is required to help to ensure child survival, in order to achieve the Millennium Development Goal 4, which is to reduce the underfive mortality rate by two-thirds between 1990 and 2015. ${ }^{2}$ Regarding the rate of current socio-economic and cultural development, it is clear that the continent of Africa has been most adversely affected by the widening global inequality in mortality rates, probably as a result of the HIV/AIDS pandemic, which has been exacerbated by prevailing economic inequities. For the two continents with the most extreme disparities in the distribution of wealth (namely, North America and Africa), the gap in life expectancy fell from 30.6 years in the period 1950 to 1955 to less than 24 years in the period 1985 to 1990 . However, such a gap has since risen again to 28.6 years, with it currently being at almost the same level as in the 1950s. ${ }^{3}$ Worldwide, accessing health care has become problematic for an increasing number of people, though especially so in developing countries. Due to globalisation, the degree of mobility and migration has increased significantly, leading to ever-increasing concentrations of the world population in the major metropolises. By 2030, it is anticipated that $70 \%$ of the world population will live in an urban environment, with the percentage being likely to be $85 \%$ by the end of the 21st century). Such a population distribution will inevitably place greater demands on the health care system, with global problems emerging on the local level (in what is known as 'glocalisation').

\section{Addressing the social determinants of health}

The report of the Commission on Social Determinants of Health, Closing the gap in a generation, ${ }^{4} \mathrm{clearly}$ describes how structural determinants lead not only to social stratification but also to differential vulnerability and exposure, as well as to health inequities. It has become clear that the health system is an intermediary 'social determinant', which makes health care providers and the related services responsible for addressing social inequities in health. ${ }^{5}$ The field of family medicine has a role to play in the social determining of health, by integrating aspects of personal health care with those in the community. ${ }^{6}$

Figure 1 illustrates how primary health care can serve as a strategy for promoting health equity and intersectoral action. Prerequisites for the implementation of such a strategy are both the maintenance of a high level of accessibility, as well as the delivery of high-quality care, by the primary health care team. Moreover, the team should interact with the most prominent networks in the key educational and economic sectors, among others. Apart from its focus on individuals and families, such a team should also focus on serving the community as a whole, utilising the community-oriented primary care (COPC) strategy. ${ }^{7}$ The utilisation of this strategy entails the systematic assessment of health care needs in the target population, the identification of community health problems, and the implementation of systematic interventions (such as the modification of practice procedures and the improvement of living conditions), involving the population. Such a strategy also entails monitoring the effect of changes to ensure that health services are improved and congruent with community needs. COPC teams design specific interventions aimed at addressing those health problems that have been prioritised. Teams, consisting of both primary health care workers and community members, assess the available resources and develop the requisite strategic plans for dealing with those problems that have been identified. COPC integrates both individualised and population-based care, utilising the clinical skills of the practitioners concerned, blended with elements of epidemiology, preventive medicine, and health promotion. The use of such a blended approach aims at narrowing the traditional gap between public health and individual health care. ${ }^{8}$

The COPC strategy, the direct action of the primary health care team and intersectoral networking serve together to enhance the social cohesion of the community. Both the curative and the preventive actions of the primary health care team, as well as the increased degree of social cohesion in the community, should lead to the empowerment of the community members concerned. Such empowerment is situated at the physical, psychological, social, and cultural levels. As the COPC interventions help to improve the living conditions of the local community, the exposure of its members to factors that might, otherwise, threaten their health should diminish, leading to a decrease in the vulnerability of the community as a whole to those factors that contribute to health inequity. An improvement in the structural determinants, which will, in turn, influence the social stratification, should come about through improvements in education, working conditions and the opening up of job opportunities, better housing conditions and enhanced access to safe food and water. In brief, the multidisciplinary primary health care team, in which the family physician should play a key role, should function as part of a network with other sectors. Such a network will then be able to promote health equity by means of increased social cohesion and empowerment. ${ }^{9}$ 


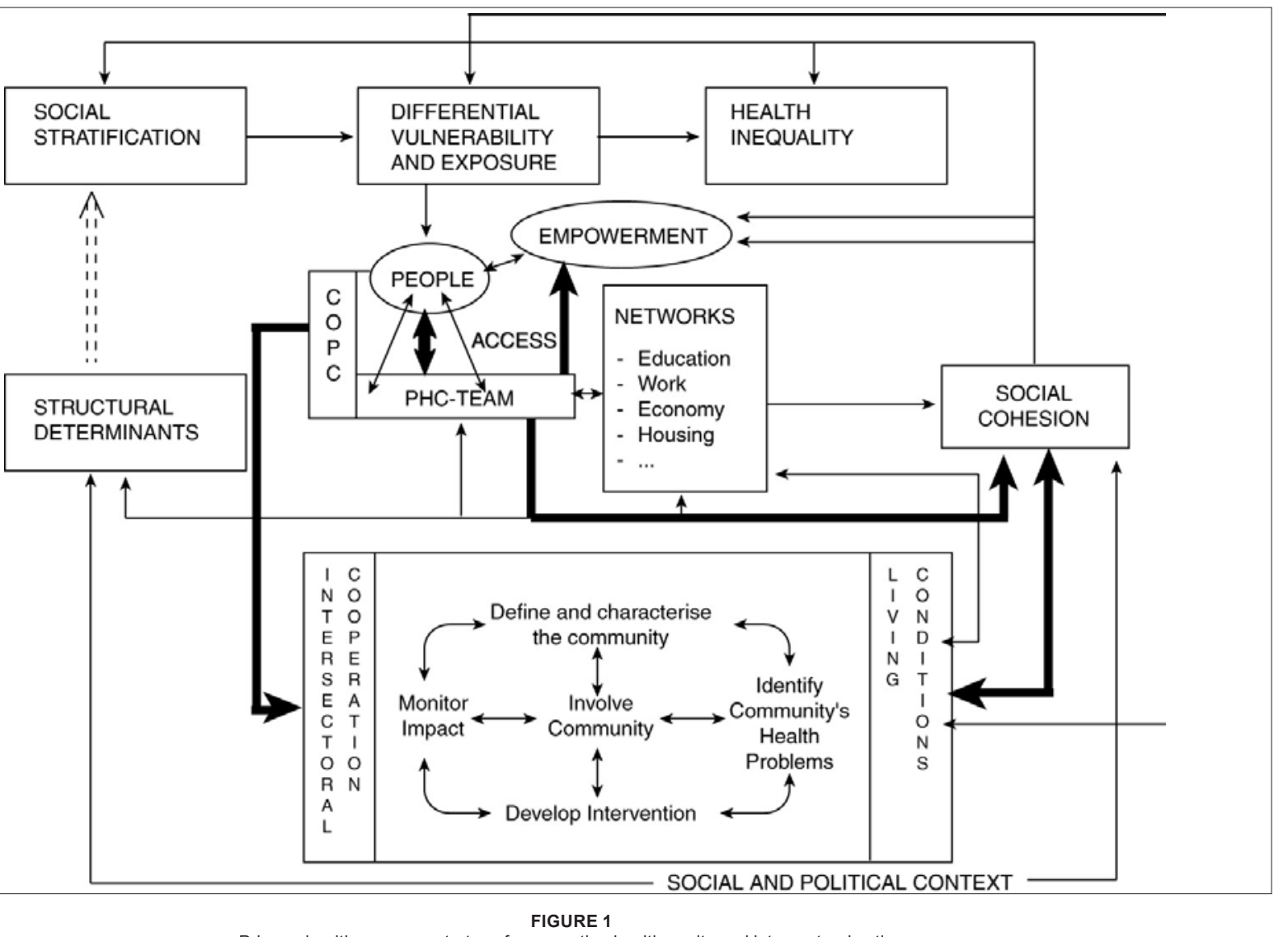

\section{Opting for change in the health care system}

Evidence $^{10}$ exists that comprehensive primary health care contributes to a high quality and cost-effective health system. Those countries with a strong primary health care system are marked by greater access to health care services, based on health needs; better overall quality of care; greater focus on prevention; a stronger emphasis on early diagnosis and the management of health problems; and a reduction in the number of unnecessary, and potentially harmful, interventions. According to the World Health Report (2008), 'Primary health care: Now more than ever!'; ; a move away from hospitalo-centrism, commercialisation and fragmentation should be made towards the extension of health equity and universal access to people-centred care, together with a continuous striving towards the maintenance of healthy communities. In order to ensure such change, the primary health care system should be transformed into one that is focused on providing continuous, comprehensive and personcentred care, which pivots around the family physician and the primary care team. Resolution WHA 62.12, 'Primary health care, including health systems',12 which was unanimously approved by the World Health Assembly in May 2009, urges member states to place individuals at the centre of health care by adopting, as appropriate, delivery models that are focused on the provision of comprehensive health care services at the local and district levels. Member states should 'train and retain adequate numbers of health workers with appropriate skill-mix, including primary health care nurses, midwifes, allied health professionals and family physicians, able to work in a multi-disciplinary context'. Moreover, the Resolution urges member states to 'encourage that vertical programs, including disease-specific programs, are developed, integrated and implemented in the context of integrated primary health care'. The selective approaches, which are adopted in many vertically administered disease-oriented programmes in Africa, often result in needless duplication of effort. Such wasted effort leads to the inefficient utilisation of the existing facilities, which tends to lead to gaps in the care of patients with multi-morbidity. The resultant undermining of government capacity, which exacerbates the existing inequities in the care of patients, worsens the existing brain drain. ${ }^{13}$ As a result, the World Organisation of Family Doctors (Wonca), in collaboration with Global Health through Education Training and Service (GHETS), The Network: Towards Unity for Health (TUFH), and the European Forum for Primary Care (EFPC), call upon funding organisations, such as the Global Fund, the World Bank, the Bill and Melinda Gates Foundation, as well as the World Health Organisation, to assign a pivotal role to primary health care in the provision of their activities, as well as to support the systematic development of the sector. Accordingly, Wonca, GHETS, TUFH and EFPC propose that, by 2015, 15\% of the budgets of those vertically administered disease-oriented programmes that are directed towards the treatment and prevention of HIV / Aids, tuberculosis and malaria, be invested in strengthening the local primary health care systems, with such a percentage being increased over time. Such an investment would improve the capacity of developing nations to address most existing health problems by way of the implementation of a generic, well-structured comprehensive primary care system (see the website http://www.15by2015.org ${ }^{14}$ in this regard). ${ }^{15}$

\section{Family medicine in the framework of primary health care teams in Africa: The Primafamed network}

The Primafamed network (http://www.primafamed.ugent. be) ${ }_{1}^{16}$ which is funded by ACP-EU-Edulink, currently provides a platform for those African educational institutions concerned with issues of primary health care and family medicine to provide training of the necessary capacity in countries such as South Africa, Sudan, Uganda, Nigeria, Ghana, the Democratic Republic of the Congo (DRC), Rwanda, Tanzania and Kenya.

Moreover, the VLIR ZEIN 2009 PR361 programme, which is funded by the Belgian government, has established a 'South 
African family medicine twinning project'. In terms of the programme, the departments of family medicine in South Africa 'twin' with those training complexes that have been or will be set up in Namibia, Zambia, Mozambique, Malawi, Lesotho, Swaziland, the DRC and Botswana. Primafamed gives support in terms of capacity-building, content development and the monitoring of postgraduate training in family medicine. The network fosters the principle of South-South cooperation, by encouraging the sharing of unique knowledge and wisdom among different African institutions, as well as by creating an institutional network among them.

\section{Challenges for primary health care in the 21st century}

The development of family medicine, as a field of endeavour, can only but benefit from the making of adequate strategic choices and from focusing on increasing access (by means of universal coverage, supported by public insurance, social security systems, and community-based health insurance programmes, among others). The reorientation of the health system from hospitalocentrism to a focus on primary health care, and the promotion of the role of the family physician within the framework of the primary health care team should help to limit both the internal and international brain drain.

Such a refocusing on primary health care should facilitate the implementation of both the commitment and the spirit of Dr Andem Ewa, the first president of the Association of General and Private Medical Practitioners of Nigeria. In this way, we should be able to bring into practice the 'message of hope', as formulated by Archbishop Emeritus Desmond Tutu, in his preface to Hugo and Allen's Doctors for tomorrow: Family medicine in South Africa: ${ }^{17}$

Doctors in family medicine are aware of the challenges, attempt to understand them better and work to address them... The issues of principles and values, relationships and meaning are not left to chance, but become an important element of service, systems, training and research.

This gives me hope of a transformation in the health service that can take care of our people, which can guide us through this difficult time. This hope is not only for South Africa, but also for our brothers and sisters in the rest of the continent and the rest of the world. If the family medicine movement can play that role, let us join hands and realise that dream.

\section{REFERENCES}

1. International Bank for Reconstruction and Development/ World Bank. Global monitoring report 2006: Millennium Development Goals: Strengthening mutual accountability, aid, trade and governance. Washington: IBRD; 2006. p. 4.

2. Horton R. A new global commitment to child survival. Lancet. 2006;368:1041-1042.

3. Dorling D, Shaw M, Smith GD. Global inequality of life expectancy due to AIDS. BMJ. 2006;332:662-664.

4. Commission on Social Determinants of Health. Closing the gap in a generation [homepage on the Internet]. 2008 [cited 6 Jan 2008]. Available from: http://whqlibdoc.who.int/ publications/2008/9789241563703_eng.pdf.

5. Willems S. The socio-economic gradient in health: A neverending story? A descriptive and explorative study in Belgium [homepage on the Internet]. 2005 [cited 2009 Sept 10]. Available from: http://www.statbel.fgov.be/studies/ ac612_612en.pdf

6. Van Weel C, De Maeseneer J, Roberts R. Integration of personal community health care. Lancet. 2008;372:871-872.

7. Art B, Deroo L, De Maeseneer J. Towards unity for health utilising community oriented primary care in education and practice. Educ Health. 2007;20:1-10.

8. Rhyne R, Bogue R, Kukulka G, Fulmer H. Communityoriented primary care: Health care for the 21st century. Washington: American Association for Public Health; 1998.
9. De Maeseneer J, Willems S, De Sutter A, Van de Geuchte I, Billings M. Primary health care as a strategy for achieving equitable care. Internal document to the Knowledge Network 'Health Systems' of the Commission on Social Determinants of Health of WHO [homepage on the Internet]. 2007 [cited no date]. Available from: http://www.WHO.INT/social_ determinants/resources/csdh_media/primary_health_ care_2007_en.pdf.

10. Starfield B, Shi L, Macinko J. Contribution of primary care to health systems and health. Milbank Quarterly. 2005;83(3):457-502.

11. World Health Organization. Primary health care: Now more than ever! [homepage on the Internet] 2008 [cited 2009 Sept 10]. Available from: http://www.who.int/whr/2008/ whr08_en.pdf.

12. World Health Assembly (WHA). Primary health care, including health systems. Resolution presented and adopted at the $62^{\text {nd }}$ World Health Assembly; 2009 May 18-22; Geneva, Switzerland.

13. De Maeseneer J, Van Weel C, Egilman D, et al. Funding for primary health care in developing countries: Money from disease specific projects could be used to strengthen primary care. BMJ. 2008;336:518-519.

14. 15 by 2015: Strengthening primary health care. [homepage on the Internet] 2009 [cited 2009 Sept 10]. Available from: http://www.15by2015.org.

15. De Maeseneer J. Strengthening primary care: Addressing the disparity between vertical and horizontal investment. $\mathrm{Br}$ J Gen Prac. 2008;58:3-4.

16. Primafamed. Ghent University Centre. International Centre for Primary Health Care and Family Medicine [homepage on the Internet]. No date [cited 2009 Sept 10]. Available from: http:/ /www.primafamed.ugent.be.

17. Tutu D. Preface: A message of hope. In: Hugo J, Allen L, editors. Doctors for tomorrow: Family medicine in South Africa. Grahamstown: NISC, 2008; p. vi-vii. 